and above all Granit passes unnoticed. "That colour blindness of the peripheral parts of the retina is only relative was demonstrated by Tschermak, a pupil of Hering, about forty years ago." As a matter of fact it was pointed out by Aubert in 1865 .

In spite of these criticisms the brochure contains much of interest to the ophthalmologist.

\title{
OBITUARY
}

\section{A. W. SANDFORD}

We regret to record the death of Arthur Wellesley Sandford on May 12. He was born in 1858 in Ireland, the son of the Rector of Clonmel. Sandford was educated privately and at Queen's College, Cork. He graduated M.D., M.Ch. in 1882 and at once began his long connection with Cork as an ophthalmic and aural surgeon. He soon acquired a great reputation all over the South of Ireland and for many years had a very large practice both in private and hospital. He held the post of Ophthalmic and Aural Surgeon to the Cork County Hospital and Southern Infirmary, and on retirement was elected Consulting Surgeon. Sandford joined the Ophthalmological Society of the United Kingdom in 1884, he served on the Council from 1896-1899 and was Vice-President, 1902-1905. On the formation of the British Journal of Ophthalmology he became our representative in South Ireland and held the post until 1922. He had also served as President of the Irish Ophthalmological Society, and as Professor of Ophthalmology and Otology at University College, Cork.

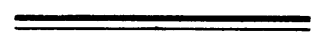

\section{NOTES}

Honour

MISS IDA MANN has been elected the first Society of Australia. honorary member of the Ophthalmological

Appointment

Hospital.
ARTHUR LiSTER has been appointed Assistant Surgeon to the Royal London Ophthalmic 